\title{
Stark broadening parameters in the S III spectrum
}

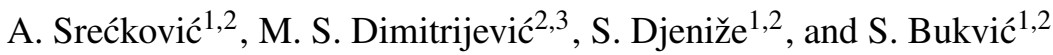 \\ 1 Faculty of Physics, University of Belgrade, 11001 Belgrade, POB 368, Serbia, Yugoslavia \\ 2 Isaac Newton Institute of Chile, Yugoslavia Branch, Belgrade, Yugoslavia \\ 3 Astronomical Observatory 11160 Belgrade, Volgina 7, Serbia, Yugoslavia \\ e-mail: steva@ff.bg.ac.yu
}

Received 2 December 2002 / Accepted 20 December 2002

\begin{abstract}
Stark widths and shifts of astrophysically important 10 doubly ionized sulfur (S III) spectral lines (within the $3 d-4 p$ and $4 \mathrm{~s}-4 \mathrm{p}$ transitions) have been measured in a $S F_{6}$ plasma created in the linear, low-pressure, pulsed arc discharge at about $35000 \mathrm{~K}$ electron temperature and about $2.8 \times 10^{23} \mathrm{~m}^{-3}$ electron density. The widths and shifts have been calculated using the semiclassical perturbation formalism (SCPF) (taking into account the impurity of energy levels, i.e. that the atomic energy levels are expressed as a mix of different configurations due to the configuration interaction), modified semiempirical (SEM) approximation, simplified semiclassical theory $(\mathrm{G})$ and its modification $(\mathrm{GM})$ taking into account new energy level values. Calculations have been performed for electron temperatures between $10000 \mathrm{~K}$ and $150000 \mathrm{~K}$ for electrons, protons and helium ions as perturbers. The measured and calculated S III shifts present the first published data in this field.
\end{abstract}

Key words. plasmas - line: profiles - atomic data

\section{Introduction}

The ionized sulfur spectral lines play an important role in astrophysics. Recently, ultra-violet line emission from S III ions has been found in the spectra emitted from the diffuse interstellar medium (Shelton 2002). S III spectral lines have been obtained, also, in spectra of galaxies with Compact H II Regions (Vermeij \& van der Hulst 2002; Martin-Hernández et al. 2002). Doubly ionized sulfur spectral lines have been used for the nebular chemical abundance diagnostics (Oey \& Shields 2000). In the works: Kwitter \& Henry (2001) and Castellanos et al. (2002) (and in many other works) presence of the S III ions was discovered in spectra of various cosmic light sources. Therefore, the S III spectral line characteristics are of interest in astrophysics. In hot stars with $T_{\text {eff }}$ around or higher than $10000 \mathrm{~K}$, the hydrogen is mainly ionized and Stark broadening is the main pressure broadening mechanism. Thus, the knowledge of the Stark broadening parameters (the width and the shift) is important for the astrophysical and laboratory plasma diagnostics or modeling (Griem 1974, 1997; Zeippen 1995; Lesage \& Fuhr 1999; Konjević et al. 2002).

In the present work we will present the first reliable Stark shift $(d)$ measurements of S III spectral lines with their first calculated values, performed by us, on the basis of the semiclassical perturbation formalism (SCPF) (taking into account the impurity of energy levels, i.e. that the atomic energy levels are expressed as a mix of different configurations due to the configuration interaction), modified

Send offprint requests to: A. Srećković, e-mail: steva@ff.bg . ac . yu semiempirical (SEM) approximation (Dimitrijević \& Konjević 1980 ) and the modification (GM) (Dimitrijević \& Konjević 1980) of the simplified semiclassical theory (G) (Eq. (526) in Griem 1974) taking into account energy level values of Johansson et al. (1992) not available for earlier calculations (Dimitrijević \& Konjević 1981; Dimitrijević 1988a,b). Calculation have been performed for electron temperatures between $10000 \mathrm{~K}$ and $150000 \mathrm{~K}$ for electrons, protons and helium ions as perturbers. Corresponding Stark FWHM (full-width at half intensity maximum, $W$ ) is also measured and calculated. Three of them are the first measured data. Our measured and calculated $W$ and $d$ values are compared to available experimental S III Stark parameters (Platiša et al. 1979; Djeniže et al. 1990).

\section{Experiment}

The linear pulsed arc that was used as plasma source was described in detail in our previous publications (Djeniže et al. 1992, 2002a,b; Srećković et al. 2001). Thus, only a few details will be given here. A pulsed discharge was occurred in a Pyrex discharge tube of $5 \mathrm{~mm}$ inner diameter and had plasma length of $6.3 \mathrm{~cm}$. The tube had quartz windows. The working gas was $S F_{6}$ at $130 \mathrm{~Pa}$ filling pressure in a flowing regime $(10 \mathrm{ml} / \mathrm{min})$. The used experimental set-up system, recording procedure and applied diagnostics methods are presented in our earlier publication (Djeniže et al. 2002b, and references therein). The absence of the self-absorption was checked using the method described in Djeniže \& Bukvić (2001). Obtained electron 


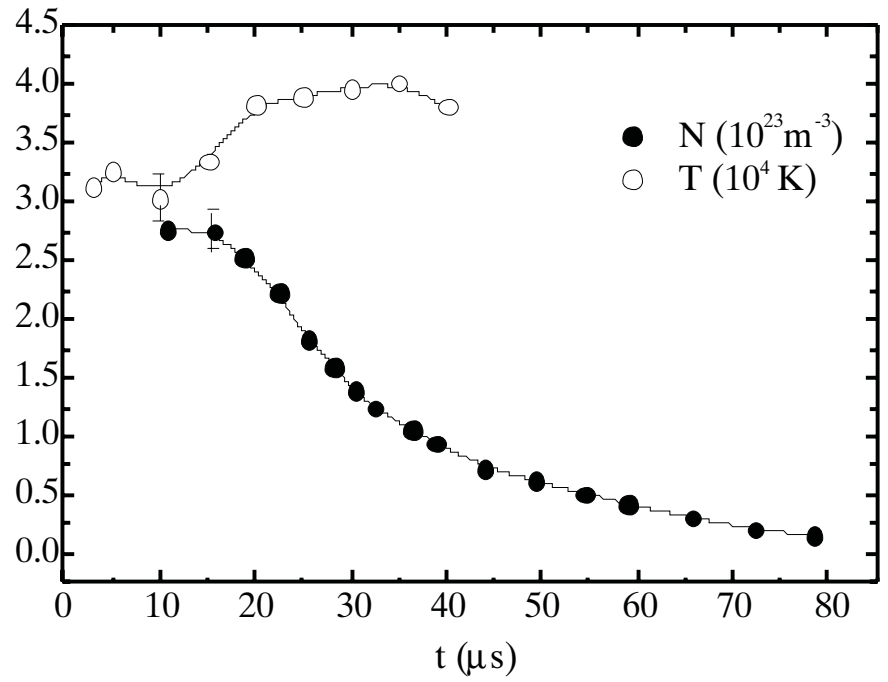

Fig. 1. Temporal evolutions of the electron temperature $(T)$ and electron density $(N)$. Error bars present $\pm 7 \%$ and $\pm 6 \%$, respectively.

temperature $(T)$ and electron density $(N)$ decays are presented in Fig. 1.

\subsection{Stark widths measurements}

The measured profiles were of the Voigt type due to the convolutions of the Lorentzian Stark and Gaussian profiles caused by Doppler and instrumental broadening. For the electron density and temperature in our experiment the Lorentzian fraction was dominant. van der Waals (Griem 1974) and resonance (Griem 1974) broadening were estimated to be smaller by more than one order of magnitude in comparison to Stark, Doppler and instrumental broadening. The standard deconvolution procedure (Davies \& Vaughan 1963) was applied using the least square algorithm. The Stark widths were measured with $\pm 12 \%$ error at a given $N$ and $T$. Our measured Stark $F W H M\left(W_{m}\right)$ are presented in Table 1.

\subsection{Stark shifts measurements}

The Stark shifts were measured relative to the unshifted spectral lines emitted by the same plasma (Djeniže et al. 2002a, and references therein). Stark shift data are corrected to the electron temperature decay (Popović et al. 1992). Our measured Stark shifts $\left(d_{m}\right)$ are presented in Table 1.

\section{Theory}

The S III Stark widths $(W)$ and shift $(d)$ values have been calculated using the semiclassical perturbation formalism (SCPF) (Sahal-Bréchot 1969a,b; 1974, 1991; Fleurier et al. 1974; Dimitrijević et al. 1991; Dimitrijević \& Sahal-Bréchot 1996a,b) taking into account the impurity of energy levels, i.e. that the atomic energy levels are expressed as a mix of different configurations due to the configuration interaction, for electrons, protons and helium ions as perturbers. We have performed, also, calculations on the basis of the modified semiempirical theory (SEM) (Dimitrijević \& Konjević 1980, 1981),
Table 1. Measured S III Stark $F W H M\left(W_{m}\right.$ in pm) and shift $\left(d_{m}\right.$ in pm) at given $T$ (in $10^{3} \mathrm{~K}$ ) and $N\left(\right.$ in $10^{23} \mathrm{~m}^{-3}$ ). Transitions and wavelengths are taken from NIST (2002). Positive shift is toward the red.

\begin{tabular}{|c|c|c|c|c|c|}
\hline $\begin{array}{l}\text { Transition } \\
\text { Multiplet }\end{array}$ & $\begin{array}{l}\lambda \\
(\mathrm{nm})\end{array}$ & $T$ & $N$ & $W_{m}$ & $d_{m}$ \\
\hline \multirow[t]{2}{*}{$\begin{array}{c}3 \mathrm{p} 3 \mathrm{~d}-3 \mathrm{p}\left({ }^{2} \mathrm{P}^{0}\right) 4 \mathrm{p} \\
{ }^{3} \mathrm{P}^{0}-{ }^{3} \mathrm{D} \\
(1)\end{array}$} & 370.9338 & $\begin{array}{l}30.4 \\
31.2 \\
33.6 \\
38.3\end{array}$ & $\begin{array}{l}2.75 \\
2.84 \\
2.80 \\
2.43\end{array}$ & $\begin{array}{l}43.1 \\
36.1 \\
36.0 \\
37.9\end{array}$ & $-1.1 \pm 0.5$ \\
\hline & 371.0422 & $\begin{array}{l}30.4 \\
31.2 \\
33.6 \\
38.3\end{array}$ & $\begin{array}{l}2.75 \\
2.84 \\
2.80 \\
2.43\end{array}$ & $\begin{array}{l}43.4 \\
44.0 \\
45.6 \\
32.9\end{array}$ & $-1.4 \pm 1.2$ \\
\hline \multirow[t]{2}{*}{$\begin{array}{c}{ }^{3} \mathrm{P}^{0}-{ }^{3} \mathrm{P} \\
(2)\end{array}$} & 337.0351 & $\begin{array}{l}30.4 \\
31.2 \\
33.6 \\
38.3\end{array}$ & $\begin{array}{l}2.75 \\
2.84 \\
2.80 \\
2.43\end{array}$ & $\begin{array}{l}51.8 \\
47.7 \\
42.1 \\
42.3\end{array}$ & $0.0 \pm 0.6$ \\
\hline & 338.7092 & $\begin{array}{l}30.4 \\
31.2 \\
33.6 \\
38.3\end{array}$ & $\begin{array}{l}2.75 \\
2.84 \\
2.80 \\
2.43\end{array}$ & $\begin{array}{l}61.5 \\
47.0 \\
46.2 \\
47.8\end{array}$ & $0.0 \pm 0.3$ \\
\hline \multirow[t]{2}{*}{$\begin{array}{c}{ }^{3} \mathrm{D}^{0}-^{3} \mathrm{P} \\
(8)\end{array}$} & 392.8556 & $\begin{array}{l}30.4 \\
31.2 \\
33.6 \\
38.3\end{array}$ & $\begin{array}{l}2.75 \\
2.84 \\
2.80 \\
2.43\end{array} \mid$ & $\begin{array}{l}68.3 \\
66.9 \\
61.8 \\
62.9\end{array}$ & $5.2 \pm 0.9$ \\
\hline & 398.3723 & $\begin{array}{l}30.4 \\
31.2 \\
33.6 \\
38.3\end{array}$ & $\begin{array}{l}2.75 \\
2.84 \\
2.80 \\
2.43\end{array}$ & $\begin{array}{l}72.5 \\
69.5 \\
74.3 \\
72.4\end{array}$ & $7.6 \pm 1.2$ \\
\hline $\begin{array}{c}3 \mathrm{p} 4 \mathrm{~s}-3 \mathrm{p}\left({ }^{2} \mathrm{P}^{0}\right) 4 \mathrm{p} \\
{ }^{3} \mathrm{P}^{0}-{ }^{3} \mathrm{P} \\
\text { (4) }\end{array}$ & 436.1468 & $\begin{array}{l}30.4 \\
31.2 \\
33.6 \\
38.3\end{array}$ & $\begin{array}{l}2.75 \\
2.84 \\
2.80 \\
2.43\end{array}$ & $\begin{array}{l}80.2 \\
66.5 \\
62.6 \\
63.0\end{array}$ & $0.3 \pm 0.1$ \\
\hline $\begin{array}{c}{ }^{3} \mathrm{P}^{0}-^{3} \mathrm{P} \\
(5)\end{array}$ & 389.9093 & $\begin{array}{l}30.4 \\
31.2 \\
33.6 \\
38.3\end{array}$ & $\begin{array}{l}2.75 \\
2.84 \\
2.80 \\
2.43\end{array}$ & $\begin{array}{l}75.5 \\
64.7 \\
64.0 \\
61.4\end{array}$ & $1.1 \pm 0.5$ \\
\hline \multirow[t]{2}{*}{$\begin{array}{c}{ }^{3} \mathrm{P}^{0}-{ }^{3} \mathrm{~S} \\
(6)\end{array}$} & 366.1942 & $\begin{array}{l}30.4 \\
31.2 \\
33.6 \\
38.3\end{array}$ & $\begin{array}{l}2.75 \\
2.84 \\
2.80 \\
2.43\end{array}$ & $\begin{array}{l}78.5 \\
79.4 \\
78.1 \\
77.0\end{array}$ & $3.7 \pm 0.7$ \\
\hline & 371.7717 & $\begin{array}{l}30.4 \\
31.2 \\
33.6 \\
38.3\end{array}$ & $\begin{array}{l}2.75 \\
2.84 \\
2.80 \\
2.43\end{array}$ & $\begin{array}{l}72.2 \\
66.9 \\
66.3 \\
63.8\end{array}$ & $1.2 \pm 0.6$ \\
\hline
\end{tabular}

and the modification (GM) (Dimitrijević \& Konjević 1980) of the simplified semiclassical theory (G) (Eq. (526) in Griem 1974). Atomic energy levels needed for calculation have been taken in Johansson et al. (1992) for electrons as perturbers, only. Calculations have been performed for electron temperatures between $10000 \mathrm{~K}$ and $150000 \mathrm{~K}$. Calculated $W$ and $d$ values are presented in Table 2. 


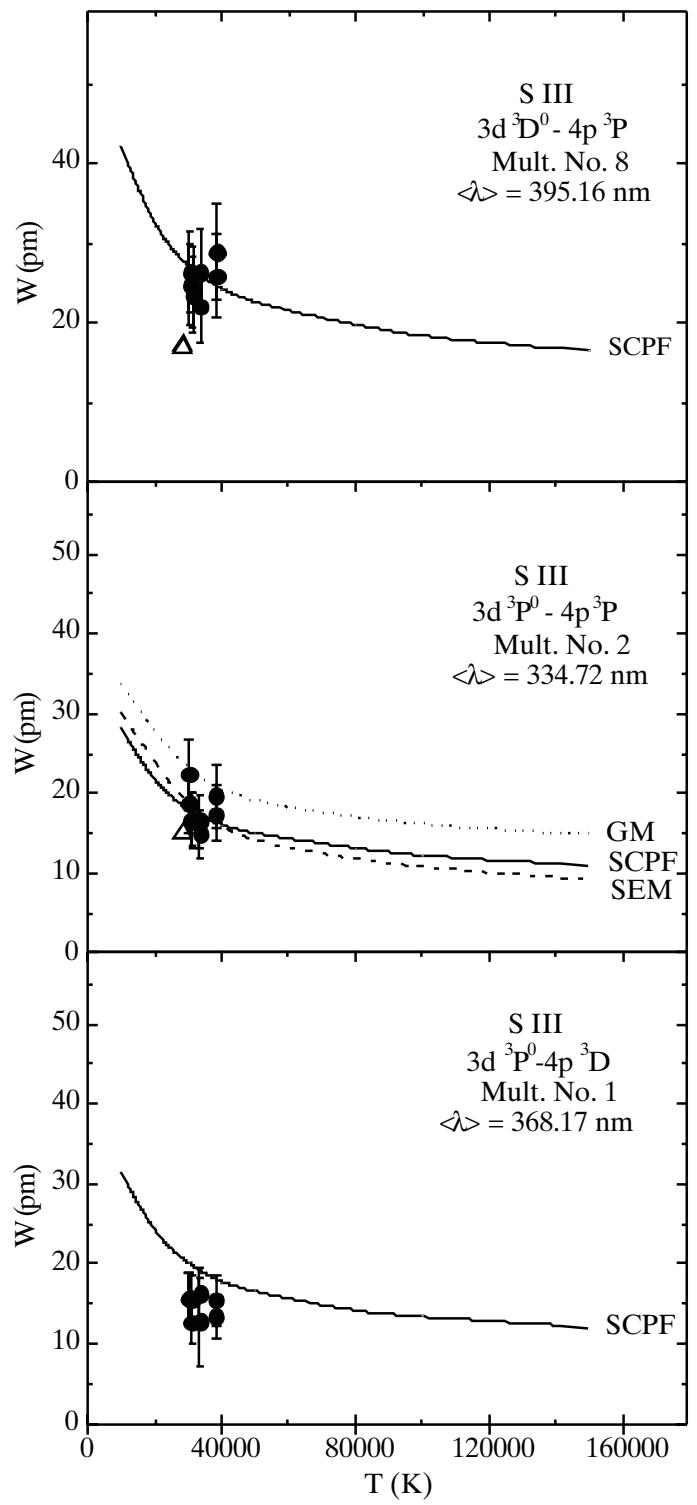

Fig. 2. Stark $F W H M\left(W\right.$ in pm) vs. electron temperature at $10^{23} \mathrm{~m}^{-3}$ electron density in the $3 d-4 p$ transition. SCPF, SEM and GM present our calculated $W$ values using semiclassical perturbation formalism, modified semiempirical approaches and simplified semiclassical theory, respectively, for electrons as perturbers. • our experimental data; $\Delta$, Platiša et al. (1979); $\bigcirc$, Djeniže et al. (1990). $\langle\lambda\rangle$ is the mean wavelength in the multiplet. Error bars represent estimated uncertainties $( \pm 18 \%)$.

\section{Results and discussion}

Our measured ( $W_{m}$ and $\left.d_{m}\right)$ and calculated ( $W$ and $d$ ) values are presented in Tables 1 and 2, respectively. For each value given in Table 2, the collision volume multiplied by perturber density is much less than one and the impact approximation is valid (Sahal-Bréchot 1969a,b). When the impact approximation is not valid, the ion broadening contribution may be estimated by using quasistatic approach (Sahal-Bréchot 1991 or Griem 1974).

In order to compare the measured and calculated Stark $F W H M$ values, we have presented in Figs. 2 and 3 existing

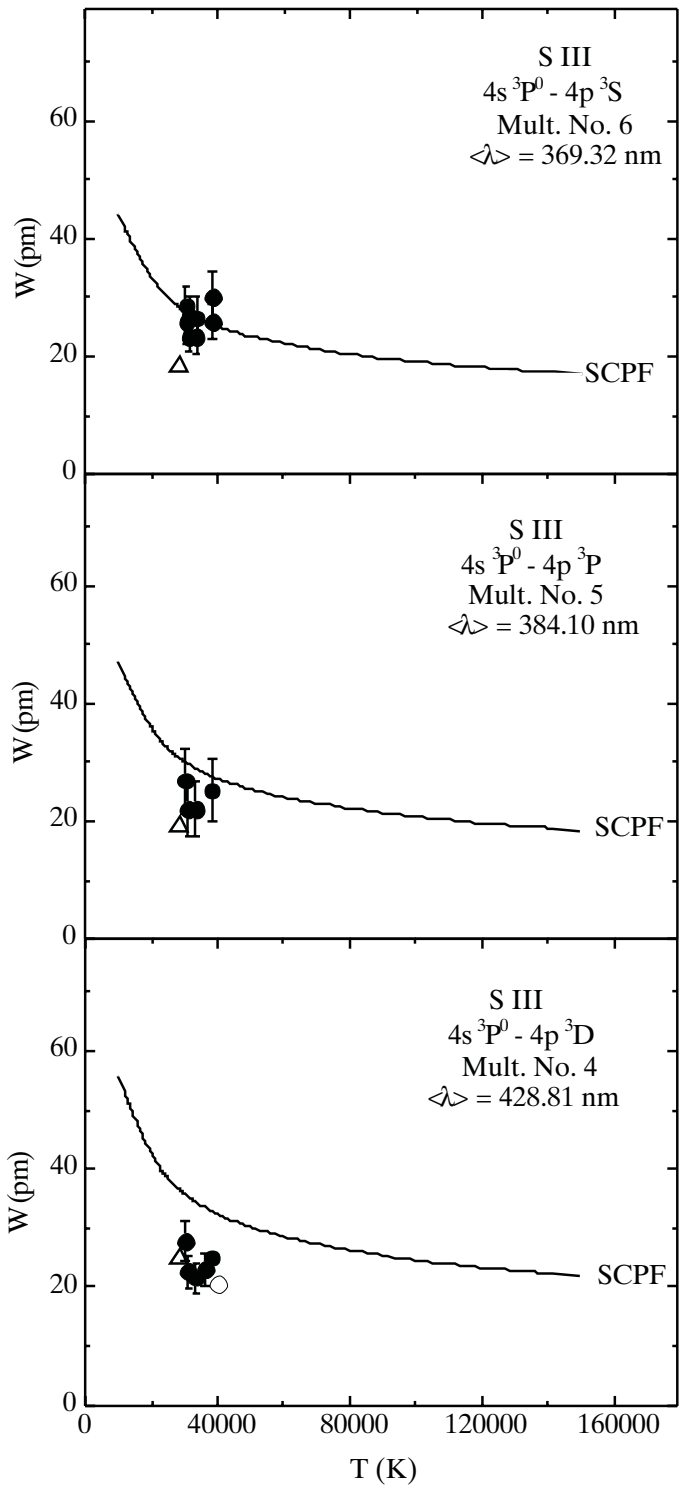

Fig. 3. Stark $F W H M\left(W\right.$ in pm) vs. electron temperature at $10^{23} \mathrm{~m}^{-3}$ electron density in the $4 \mathrm{~s}-4 \mathrm{p}$ transition. The symbols are the same as in Fig. 2.

experimental data set including our results, together with our theoretical predictions.

On the basis of the found $W$ and $d$ values one can conclude:

Very good agreement was found among our measured and calculated (SCPF) $W$ values in the $3 d-4 p$ and $4 s-4 p$ transitions except in the multiplet No. 4 where SCPF values overvalue experimental data at about $35 \%$. It turns out that SEM and GM $W$ values also agree with our $W_{m}$ data (see Fig. 2).

We have found that Stark width generated by electrons is dominant and the proton and helium ion contributions to the total Stark width can be neglected up to $150000 \mathrm{~K}$ temperature.

Our calculated $d$ values are very small. In the case of the $3 d-4 p$ transition they are practically equal to zero (within the uncertainties of the theory). In the case of the $4 s-4 p$ transition they are about $2 \mathrm{pm}$. Measured $d_{m}$ values are also small. In the $4 s-4 p$ transition they show different sign in comparison to calculated ones. Evident finite $d_{m}$ values are found in the case of 
Table 2. Calculated S III Stark $F W H M(W$ in pm) and shift ( $d$ in pm) for electrons (a), protons (b) and helium ions (c) as preturbers for various plasma temperatures $\left(T\right.$ in $10^{4} \mathrm{~K}$ ) and $10^{23} \mathrm{~m}^{-3}$ perturber density. A, B and C denote values obtained by semiclassical perturbation formalism (SCPF), modified semiempirical method (SEM) and modified simplified semiclassical theory (GM), respectively. Positive shift is toward the red. $\langle\lambda\rangle$ is the mean wavelength in the multiplet. For each value given in Table 2, the collision volume multiplied by perturber density is much less than one and the impact approximation is valid (Sahal-Bréchot 1969a,b). When the impact approximation is not valid, the ion broadening contribution may be estimated by using quasistatic approach (Sahal-Bréchot 1991 or Griem 1974).

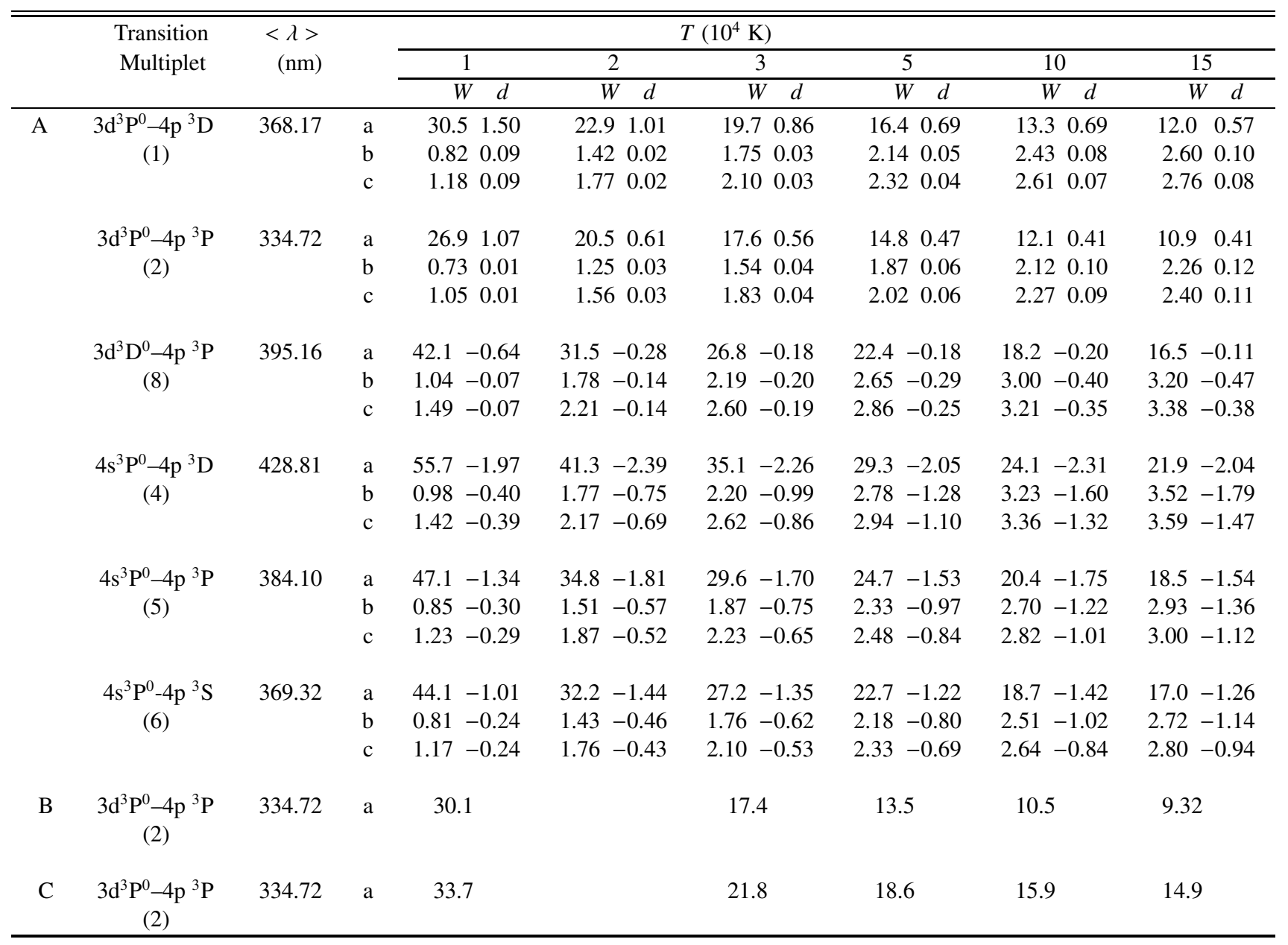

the multiplet No. 8 in the $3 \mathrm{~d}-4 \mathrm{p}$ transition. It should be noted that within the semiclassical perturbation approach, dipole contributions to the width are positive while the corresponding contribution to the shift have different signs. Consequently, if the width and shift values are of the same order of magnitude, the accuracy is also the same. However, if due to mutual cancelations of contributions with different signs, shift values are smaller for an order of magnitude or even more, as is the case here, the accuracy of such shift values are smaller. A reasonable estimate is to take as the error bars for theoretical shifts \pm 30 percent of the corresponding width value, which indicates that in the present case uncertainties of theoretical shifts are such that different signs for small theoretical and experimental shifts are without meaning. Consequently, one can consider measured shift values more reliable for further applications.

\section{Conclusion}

We have found a dominant contribution of the electron impact in comparison with proton and ionized helium impact to the total Stark width of the S III lines belonging to the $3 d-4 p$ and $4 \mathrm{~s}-4 \mathrm{p}$ transitions. Protons and helium ions generate small Stark widths which can be neglected for lines considered up to a temperature of $150000 \mathrm{~K}$.

On the basis of the found agreement among measured and calculated $W$ and $d$ values we recommend the $337.0351 \mathrm{~nm}$ and $338.7092 \mathrm{~nm}$ S III spectral lines as lines with convenient Stark broadening parameters in astrophysical plasma diagnostics.

Acknowledgements. This work is a part of the projects "Determination of the atomic parameters on the basis of the spectral line profiles" and "Influence of collision processes on astrophysical plasma lineshapes" supported in part by the Ministry of Science, Technologies and Development of the Republic of Serbia.

\section{References}

Castellanos, M., Diaz, A. I., \& Tenorio-Tagle, G. 2002, ApJ, 565, L79

Davies, J. I., \& Vaughan, J. M. 1963, ApJ, 137, 1302

Dimitrijević, M. S., \& Konjević, N. 1980, JQSRT, 24, 451 
Dimitrijević, M. S., \& Konjević, N. 1981, in Spectral Line Shapes, vol. 1, ed. B. Wende (Walter de Gruyter \& Co., New York), 211

Dimitrijević, M. S. 1988a, A\&A, 76, 53

Dimitrijević, M. S. 1988b, Bul. Obs. Astron. Belgrade, 139, 31

Dimitrijević, M. S., Sahal-Bréchot, S., \& Bommier, V. 1991, A\&AS, 89,581

Dimitrijević, M. S., \& Sahal-Bréchot, S. 1996a, Phys. Scr., 54, 50

Dimitrijević, M. S., \& Sahal-Bréchot, S. 1996b, A\&A, 119, 369

Djeniže, S., Srećković, A., Platiša, M., et al. 1990, Phys. Rev. A, 42, 2379

Djeniže, S., Srećković, A., \& Labat, J. 1992, A\&A, 253, 632

Djeniže, S., \& Bukvić, S. 2001, A\&A, 365, 252

Djeniže, S., Milosavljević, V., \& Dimitrijević, M. S. 2002a, A\&A, 382, 359

Djeniže, S., Srećković, A., Jelisavčić, M., \& Bukvić, S. 2002b, A\&A, 389, 1086

Fleurier, C., Sahal-Bréchot, S., \& Chapelle, J. 1977, JQSRT, 17, 595

Griem, H. R. 1974, Spectral Line Broadening by Plasmas (New York: Academic Press)

Griem, H. R. 1997, Principles of Plasma Spectroscopy (Cambridge: Univ. Press Cambridge)

Johansson, L., Magnusson, C. E., Joelsson, I., \& Zetterberg, P. O. 1992, Phys. Scr., 46, 221
Konjević, N., Lesage, A., Fuhr, J. R., \& Wiese, W. L. 2002, J. Phys. Chem. Ref. Data, 31, 3, 819

Kwitter, K. B., \& Henry, R. B. C. 2001, ApJ, 562, 804

Lesage, A., \& Fuhr, J. R. 1999, Bibliography of Atomic Line Shapes and Shifts (April 1992 through June 1999), Observatoire de Paris

Martin-Hernández, N. L., Peeters, E., Morisset, C., et al. 2002, A\&A, 381,606

NIST-Atomic Spectra Database Lines Data, 2002 (Wavelengths ordered)

Oey, M. S., \& Shields, J. C. 2000, ApJ, 539, 687

Platiša, M., Popović, M., Dimitrijević, M. S., \& Konjević, N. 1979, JQSRT, 22, 333

Popović, L. Č., Srećković, A., \& Djeniže, S. 1992, Proc. of the 11th ICSLS, A25, Carry le Rouet, France

Sahal-Bréchot, S. 1969a, A\&A, 1, 91

Sahal-Bréchot, S. 1969b, A\&A, 2, 322

Sahal-Bréchot, S. 1974, A\&A, 35, 321

Sahal-Bréchot, S. 1991, A\&A, 245, 322

Shelton, R. L. 2002, ApJ, 569, 758

Srećković, A., Dimitrijević, M. S., \& Djeniže, S. 2001, A\&A, 371, 354

Vermeij, R., \& van der Hulst, J. M. 2002, A\&A, 391, 1081

Zeippen, C. J. 1995, Phys. Scr., 58, 43 